\title{
A Simple Approach for the Design of Ductile Earthquake-Resisting Frame Structures Counting for P-Delta Effect
}

\author{
Rafael Shehu 1,*, Grigor Angjeliu ${ }^{2}(\mathbb{D})$ and Huseyin Bilgin ${ }^{3}(\mathbb{D}$ \\ 1 Department of Architecture, Built Environment and Construction Engineering, Politecnico Di Milano, \\ 20133 Milan, Italy \\ 2 Department of Civil and Environmental Engineering, Politecnico Di Milano, 20133 Milan, Italy; \\ grigor.angjeliu@polimi.it \\ 3 Department of Civil Engineering, EPOKA University, 1000 Tirana, Albania; hbilgin@epoka.edu.al \\ * Correspondence: rafael.shehu@polimi.it
}

Received: 9 July 2019; Accepted: 29 September 2019; Published: 8 October 2019

\begin{abstract}
In the last decades, the possibility to use the inelastic capacities of structures have driven the seismic design philosophy to conceive structures with ductile elements, able to obtain large deformations without compromising structural safety. In particular, the utilization of high-strength elements combined with the purpose of reducing inertial masses of the construction has highlighted the second-order effect as a result of the "lightweight" structure's flexibility. Computational aspects of inclusion of the second-order effects in the structural analysis remain an open issue and the most common method in the current design practices uses the stability coefficient $\theta$ The stability coefficient estimates the ratio between the second-order effect and lateral loads' effects. This coefficient is used then to amplify the lateral loads' effects in order to consider the second-order effects, within a certain range proposed by codes of practices. In the present paper, we propose a simple approach, as an alternative to the stability coefficient method, in order to take into consideration P-Delta effects for earthquake-resisting ductile frame structures in the design process. The expected plastic deformations, which can be assessed by the behavior factor and the elastic deformations of the structure, are expected to magnify the P-Delta effects compared to those estimated from an elastic approach. The real internal forces are approximated by modifying the stiffness matrix of the structure in such a way as to provide a compatible amplification effect. This concept is herein implemented with a three-step procedure and illustrated with well-documented case studies from the current literature. The obtained results show that the method, although simple, provides a good approximation compared to more refined and computationally expensive methods. The proposed method seems promising for facilitating the design computations and increasing the accuracy of the internal forces considering the second-order effects and the amplification from the inelastic deformations.
\end{abstract}

Keywords: P-Delta; steel structures; seismic design; ductility; behavior factor; stability coefficient

\section{Introduction}

The primary objective of earthquake engineering is to provide an adequate margin of safety against earthquake loads. According to performance-based seismic design, any structure adequately designed should fulfill a multilevel performance criterion, where of particular importance is guaranteeing the life safety and the collapse prevention of the structure [1]. However, collapse prevention is not a simple goal, which will always demand the acceptance of a small probability of collapse. Acceptance of this small probability of collapse requires the ability to predict, with sufficient confidence, the structural behavior until collapse. Observations of collapsed buildings in past earthquakes show that two modes 
of collapse can be envisioned for a typical building: (i) sidesway collapse and (ii) vertical collapse [2]. This statement is true not only for frame structures, but for any complex structures which may exhibit atypical collapse configurations; refer to [3] for masonry monumental structures, or to [4] (the abacus of vulnerability classification of buildings). The lateral collapse is initiated by the horizontal loads acting on the structure, either by seismic events or strong winds, until the lateral strength capacity of the structural elements is exceeded. Analyzing whether it is technically and economically possible to balance the seismic input, the designer may decide to adopt several choices, referring to [5], of which the more frequently embraced is the incrementation of the dissipated hysteretic energy by increasing the structural ductility. On the other hand, a ductile design leads to the evolution of large interstory drifts due to the advancement of plastic deformations. A progressive reduction of the load-carrying capacity of structural components that are part of the building's lateral-load-resisting system may occur to the extent that second-order $(P-\Delta)$ effects overcome gravity load resistance. P-Delta effects can significantly increase displacements and internal member forces in the postyield response of a structure [6,7], even when the vertical load magnitude is at low relative values $[8,9]$. $P-\Delta$ effects should, therefore, be accounted for in the nonlinear analysis, even when elastic design provisions would otherwise allow them to be neglected [8-13].

This paper is concerned with sidesway collapse of structures vulnerable to earthquakes and sensitive to P-Delta effects. A simplified approach is proposed for the structural design, which considers simultaneously plastic deformations and the P-Delta effect. A special interest has been shown by researchers in the past decades in deformation estimation, by refining the numerical models' nonlinear behavior with more advanced approaches. Despite the advancement made in nonlinear analyses, which are mostly used for the structural performance assessment, the design procedures are fundamentally based on linear analysis. To avoid inelastic structural analysis in design, the capacity of the structure to dissipate energy, through the ductile behavior of its elements and/or other mechanisms, is taken into account by performing an elastic analysis based on a response spectrum reduced with respect to the elastic one, by introducing the behavior factor q [14]. The behavior factor is a predefined coefficient based on the expected inelastic behavior that a structural typology exhibits during earthquakes. It considers the development of the plastic deformations, the ductile properties, and redundancy of the structure. Essentially, based on the equal displacement performance approach, it permits reducing the design earthquake loads compared to an elastic structure, assuming to achieve both the same seismic demand in displacement terms. The linear analyses, adopted in the design process of estimating the internal actions, may count for any nonlinearity by means of two approaches: (i) iterative procedures or (ii) simplified methods. Both are fundamentally based on the structural reanalysis approach [15]. The difference stands in the possibility to implement them within a subroutine for practical purposes. The simplified methods principally distinguish the responses from vertical and horizontal loads. Then, in a second step, they combine the deformations resulting from horizontal loads (wind or earthquake) with the axial loads to estimate the $P-\Delta$ effect. The drawback of the simplified methods is the lack of practicality for large and complex systems. Meanwhile, in an iterative procedure, the estimated plastic deformations do not represent an equilibrium state of the structure, due to linear analysis limitations. Thenceforth, the second-order effect which is related to the above-estimated deformations is an approximation of the real solution. The contribution of the $P-\Delta$ effect is usually estimated by the stability coefficient $\theta$, as detailed in the following paragraphs.

An amplification of the second-order moment, proportional to the evolution of plastic deformations, may be easily observed for ductile structures during strong earthquakes. Such a phenomenon is difficult to be traced during the design process with the stability coefficient only, despite that inelastic deformations can be approximated by amplifying the elastic deformations with the behavior factor $\mathrm{q}$. In the present research, a simplified approach, which may be easily implemented in many commercial software programs in order to directly obtain the design forces in structures vulnerable to $P$ - $\Delta$ effects, is provided. To overcome the design procedures and computational efforts, an enhancement of the main concept presented in [16] for SDOF (Single Degree of Freedom) systems, for what concerns MDOF 
(Multi Degree of Freedom) systems and linear dynamic analysis, is here developed and illustrated for different case studies from the literature. The proposed method differs conceptually from the current P-Delta analysis and the captured structural behavior is, from the physics point of view, more reliable. With a three-step procedure, the method is semiautomatic and very practical. The approach is adequate for a moment-resisting structural system and could be a relevant instrument for the practitioners involved in the design process.

\section{The P-Delta Inelastic Analysis}

\subsection{The SDOF System}

Figure 1 illustrates the classic example of a cantilever column subjected to equivalent horizontal load $H$ and the vertical load $P$. In the deformed configuration, an additional moment equal to the product $P \cdot \Delta$ is produced and acts on the cantilever. In the present paper, in order to study this effect employing simplified approaches, as will be explained in the following paragraphs, only one iteration will be applied for the case studies.

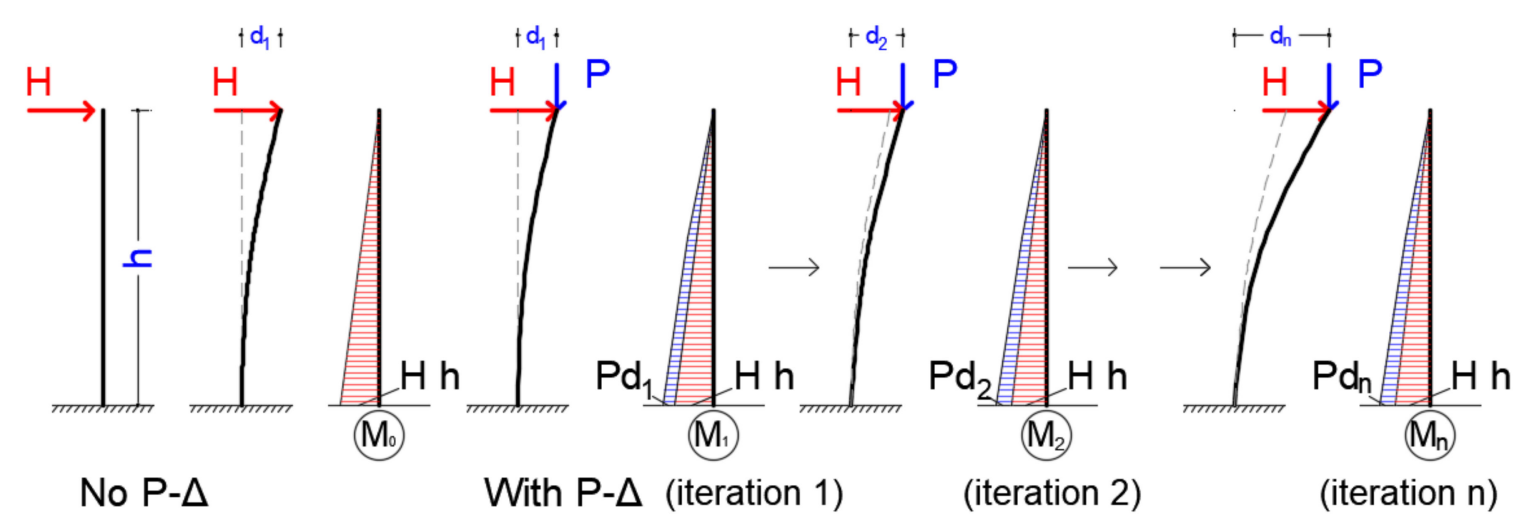

Figure 1. Forces acting on a column type element in the deformed configuration.

The effect of $P-\triangle$ becomes important when the increase of the bending moment in the columns due to the lateral deformation during an earthquake reaches a critical value [17]. According to the technical codes (e.g., [14]), this effect need not be taken into account if the following condition is fulfilled in all stories:

$$
\theta=\frac{P_{t o t} d_{r}}{V_{t o t} h} \leq 0.1
$$

where:

$\theta$ is the interstory drift sensitivity coefficient or the stability coefficient;

$P_{\text {tot }}$ is the total gravity load above the considered story in the seismic design combination;

$d_{r}$ is the design interstory drift, evaluated as the difference of the average lateral displacements at the top and bottom of the story under consideration;

$V_{\text {tot }}$ is the total seismic story shear;

and $h$ is the story height.

It is worth noting that the interstory drift should consider the evolution of possible plastic deformations induced by the seismic forces. If linear analyses are performed, as in the normal practice of structural design, the displacements shall be calculated on the basis of the elastic deformations of the structural system by means of the following simplified expression [14]:

$$
d_{s}=q_{d} d_{e}
$$

where: 
$d_{s}$ is the displacement of a point of the structural system induced by the seismic design actions; $q_{d}$ is the displacement behavior factor, assumed equal to q unless otherwise specified;

$d_{e}$ is the displacement of the same point of the structural system, as determined by a linear analysis based on the design response spectrum.

In this case, the drift at a certain level $i$ is: $d_{r, i}=d_{s, i}-d_{s, i-1}=q_{d}\left(d_{e, i}-d_{e, i-1}\right)$.

If $0.1 \leq \theta \leq 0.2$, the $P$ - $\Delta$ effects may be approximately accounted for by multiplying the relevant seismic action effects by a factor equal to $1 /(1-\theta)$. If $\theta \geq 0.2$, an exact second-order analysis is required [18]. In any case, it is recommended to keep $\theta \leq 0.3$ otherwise the conceptual design of the considered structure is not adequate $[1,14,19]$. Figure 2a depicts the implication of the interstory drift sensitivity coefficient into the (i) reduction of the stiffness, (ii) reduction of the strength capacity of the first yield, and (iii) the progressive strength decay to a residual strength corresponding to the ultimate lateral displacement. Performance-Based Seismic Design (PBSD) is currently the predominant design concept being applied in seismic design on any structure subjected to earthquakes [20-22]. From Figure 2a, it is evident that for a designed structure, the performance objectives (i.e., in this case, the maximum displacement) cannot be achieved if the structure is not properly accounting for the second-order effects. As a matter of fact, there are many parameters involved but are out of the scope of this research, thence have not been considered here.

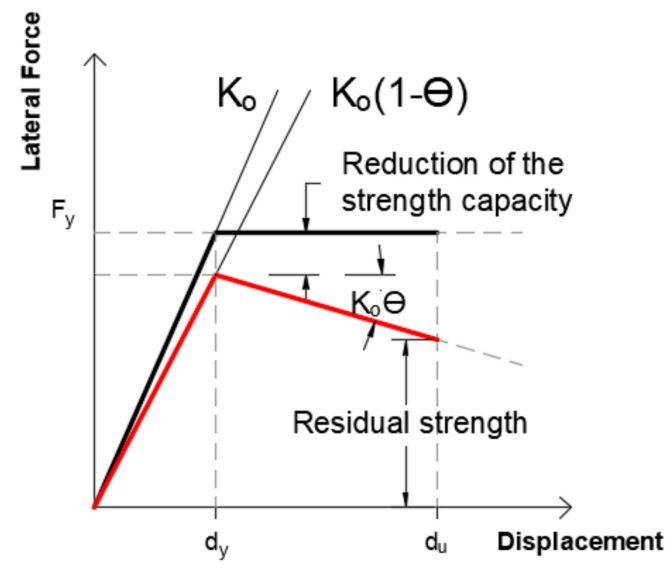

(a)

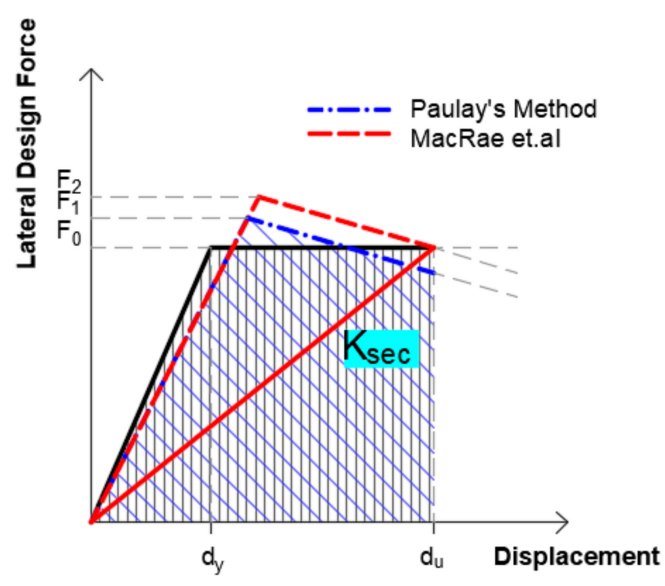

(b)

Figure 2. (a) Lateral force-displacement relationship with and without $P-\Delta$ effect; (b) design approaches under $P-\triangle$ effects.

To meet the performance objective, one may follow different approaches, of which two classics are reported in Figure 2b. Increasing the stiffness of a structure as a means of compensating the secondary effect would likely move the structure to a period with a larger seismic response and therefore it may be preferable to increase the strength instead [17], referring to Paulay's method (Figure 2b). Alternatively based on the concept of effective fundamental period and effective damping, the strength should be increased so that the secant stiffness at the peak displacement is the same for structures including and ignoring the $P-\Delta$ effect $[12,17]$, referring to MacRae's method (Figure 2b). As both methods refer to fixed target performance, they do differ in the estimation of the lateral design force. Paulay's method is compatible with the design code which proposes to increase the design seismic action by the correcting factor equal to $1 /(1-\theta)$. The second approach requires the modification of the stiffness matrix to match the estimated secant stiffness. In a static approach, the method is very straightforward, however, dynamic forces are very sensitive to the period change of the structures which may lead to incompatible actions for the primary performance objectives. In addition, the first approach amplifies all the lateral seismic loads and not localized effects on those elements when the $P-\Delta$ effect is significantly present. This can lead to an overestimation of the second-order effects. 
For an elastic static response, the stability coefficient is a straightforward measure of force and displacement amplification at the story level, however, for inelastic dynamic behavior, it is merely an indicator of the potential severity of P-Delta effects [11,23]. Many flaws could be encountered in this approach, related to post-elastic effects, dynamic stiffness, force redistribution, higher mode effects, and so forth. In this light, clearly there is a gap between this approach and a much more reliable estimation of the structural elements sensitive to $P-\Delta$ effects and inelastic deformations.

To show the difficulties of the numerical approach for the problem under investigation, we consider the case of the compressed element subjected to lateral loads. The lateral stiffness of the rod reduces significantly and a small lateral load may cause the rod to buckle. The general formulation of the static equilibrium is given by the following expression considering a stiffness matrix that takes into consideration the elastic properties of the elements and the deformed geometry according to [24]. The following equation does not consider the plastic deformations, thenceforth the following equilibrium is not conformed with the design practice for a ductile conception of the structure. The next section describes our proposal to approximate the equilibrium in the damaged phase.

$$
\left\{\begin{array}{c}
F_{i} \\
M_{i} \\
F_{j} \\
M_{j}
\end{array}\right\}=\left(\frac{E I}{L^{3}}\left[\begin{array}{cccc}
12 & 6 L & -12 & 6 L \\
& 4 L^{2} & -6 L & -2 L^{2} \\
& & 12 & 6 L \\
\operatorname{sim} & & 4 L^{2}
\end{array}\right]+\frac{P}{30 L}\left[\begin{array}{cccc}
36 & 3 L & -36 & 3 L \\
& 4 L^{2} & -3 L & -2 L^{2} \\
& & 36 & 3 L \\
\operatorname{sim} & & 4 L^{2}
\end{array}\right]\right)\left\{\begin{array}{c}
u_{i} \\
\varphi_{i} \\
u_{j} \\
\varphi_{j}
\end{array}\right\}
$$

\subsection{The P-Delta Effect and the Behavior Factor ( $q$ )}

Inelastic story drifts are directly related to ductility demands in plastic hinges, thus when drift increases in the lower stories of a frame due to $P$ - $\Delta$ effects, the plastic rotational demand increases correspondingly [25]. The ductility factor itself is not directly integrated into the seismic analysis; instead of it, the strength reduction factor is used to build the design seismic spectrum, which coincides with the so-called behavior factor. If a constant ductility is assumed, for long period structures, the strength reduction factor and the ductility are basically equal $[6,26,27]$. The current seismic design uses the behavior factor $\mathrm{q}$ to estimate the strength reduction factor, which is an approximation of the ratio of the seismic forces that the structure would experience if its response was completely elastic with $5 \%$ viscous damping, to the seismic forces that may be used in the design.

The $P-\triangle$ effect in the moment increment for an elastic SDOF system, as depicted in Figure 3, can be estimated in two different ways:

(a) Apply simultaneously the lateral and vertical loads and implement the stiffness matrix according to Equation (2).

(b) Apply the vertical loads in the system and use the resulting stiffness matrix in a second step where the lateral loads are then applied. This approach is the key to the here-proposed method.

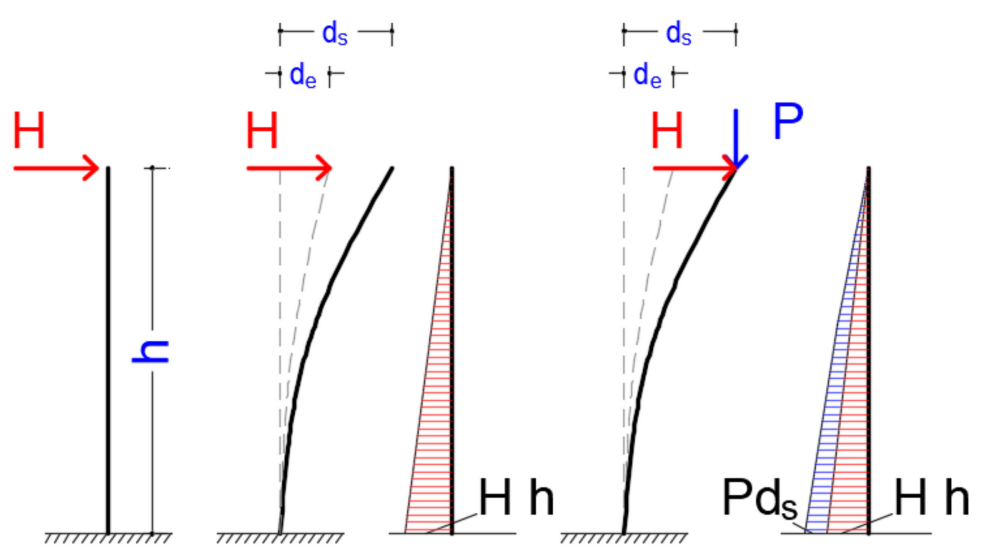

Figure 3. Static equilibrium of a cantilever in the deformed configuration. 
From the above approaches, the second one is more suitable in closed code commercial software. A single nonlinear analysis with $P-\Delta$ effect is performed initially, and then multiple combinations of horizontal loads may be applied from the previous step, counting for all the required load combinations. Both the above approaches estimate the total displacement and the total acting moment at the base of the cantilever equal to $d_{e}$ and $M=H h+P d_{e}$, respectively. For an elastoplastic system conceived according to proper seismic design, the total displacement is $q$ times higher than the corresponding elastic displacements. From that, it will be expected that an extra moment from the inelastic lateral shift of the vertically applied load will be active, $M_{q}=H h+P d_{s}$.

$$
\Delta M=M_{q}-H h=P\left(d_{s}\right)=P\left(q d_{e}\right)
$$

The magnitude of the $\Delta M$, as shown from Equation (5), is proportional to the vertical loads, the behavior factor, and the elastic displacements. From these parameters, the behavior factor is the most relevant because it influences both the plastic and elastic displacements, hence the structural design process itself. Such a phenomenon is worth being investigated for slender elements designed to undergo large plastic deformations subjected to relatively high vertical loads. These situations may be found very often in the steel moment-resisting frames of high-rise buildings. According to the second approach, the correcting moment may be approximated with the added moment in the elastic system by multiplying the vertical load instead of the displacement.

$$
\Delta M=P q d_{e}=(q P) d_{e}=P^{*} d_{e}
$$

To illustrate this approach, the example of Figure 3 is considered with a vertical load of $200 \mathrm{kN}$ and a horizontal load of $10 \mathrm{kN}$; Figure $4 \mathrm{a}, \mathrm{b}$ represents the moment diagram due to the horizontal load considering the $P-\Delta$ effect. Figure $4 \mathrm{c}$, d depicts respectively the deformed shape under horizontal load and the axial load in the element. Figure 4e represents the moment diagram due to the horizontal load considering a stiffness matrix of the element with the $P-\Delta$ effect. By comparing results from Figure $4 \mathrm{~b}, \mathrm{e}$, it can be noted that the approach is quite accurate for practical application. If we assume that this element undergoes plastic deformation, the estimated deformation in Figure $4 \mathrm{c}$ is magnified by $q$. Assuming a value for the behavior factor equal to 4 , the displacement at the ultimate state is $u_{\max }=4 \cdot 0.0071=0.0284$. The $P-\Delta$ effect in this case approximately will produce an extra moment of $\Delta M=P q d_{e}=5.68 \mathrm{kNm}$. Automatically, the moment value acting in the final configuration of the element is estimated as $M=37.29 \mathrm{kNm}$ (see Figure $4 \mathrm{f}$ ) and is more accurate than manually estimated without iterations.

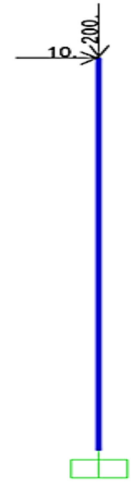

(a)

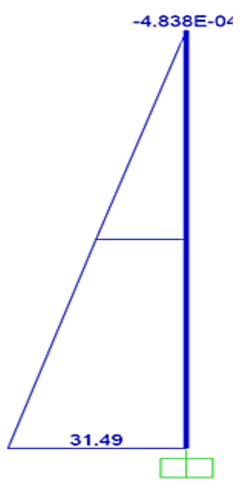

(b)

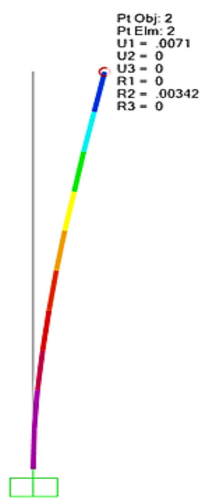

(c)

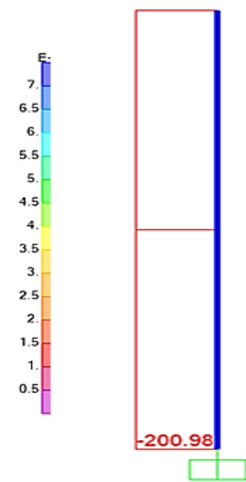

(d)

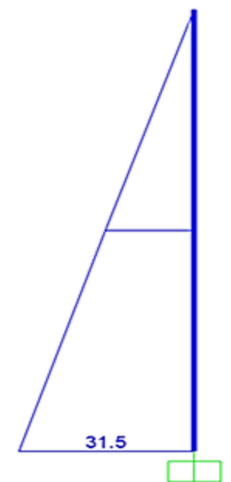

(e)

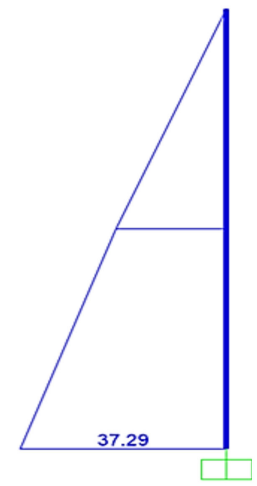

(f)

Figure 4. Illustration of the $\mathrm{q}$ factor in $P-\Delta$ effect in a cantilever: (a) applied loads; (b) moment diagram with $P$ - $\Delta$ effect; (c) deformed configuration due to lateral loads; (d) axial load in the element; (e) moment diagram with implicit $P-\Delta$ effect in the stiffness matrix; (f) moment diagram with implicit $P-\Delta$ effect in the stiffness matrix considering the amplification from the behavior factor. 
The above-estimated values conform with the interstory drift sensitivity coefficient, $\theta=$ $P_{\text {tot }} d_{r} / V_{\text {tot }} h \leq 0.189<0.2$. Therefore, a modified horizontal load $H^{*}=H /(1-\theta)=12.34 \mathrm{can}$ be applied, and the moment at the base is equal to $M=37.02 \mathrm{kNm}$. Comparing these two approaches, the $\theta$ method could overestimate the acting shear loads in the element up to a maximum of $25 \%$ related to the limit $\theta=0.2$, while the moment from the proposed approach and the stability factor approach is similar. In addition, for multi-degree-of-freedom systems, the interstory drift is not a constant parameter, thence the applicability of this approach by correcting the horizontal forces either could be computationally demanding or would result in overestimation of the shear forces.

\subsection{The P-Delta Effect on MDOF Systems}

The 10-story steel moment-resisting frame from Anderson and Bertero [28] is investigated as an illustrative example to evaluate the implementation of the proposed approach for MDOF systems. The designed elements are typical wide-flanged steel beams of different sections (Figure 5a). The bay widths are $6 m(20 \mathrm{ft})$ and the typical story height is $3.66 \mathrm{~m}(12 \mathrm{ft})$, with $4.57 \mathrm{~m}(15 \mathrm{ft})$ only for the first story. Gravity loads used in the design are: dead load $29 \mathrm{kN} / \mathrm{m}$ and live load $4.6 \mathrm{kN} / \mathrm{m}$ for the roof, and dead load $35 \mathrm{kN} / \mathrm{m}$ and live load $16 \mathrm{kN} / \mathrm{m}$ for the floors (Figure $5 \mathrm{~b}, \mathrm{c}$ ).

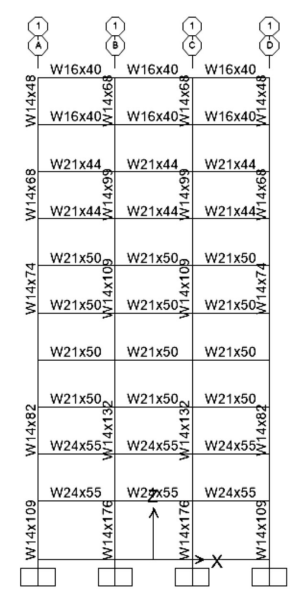

(a)

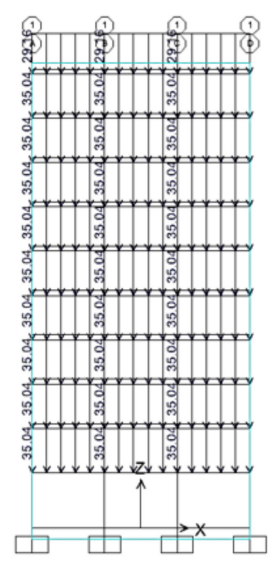

(b)

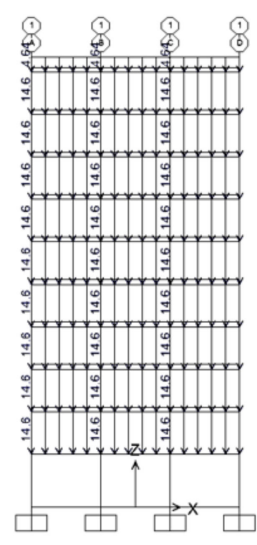

(c)

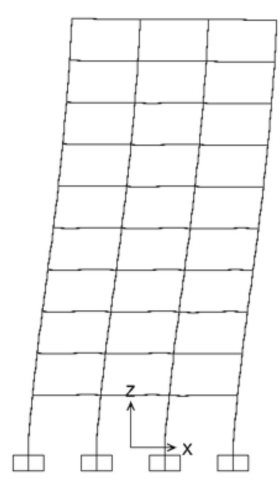

(d)

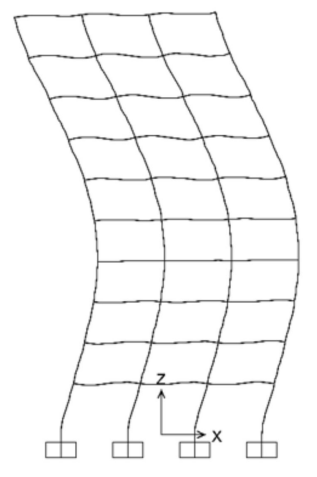

(e)

Figure 5. Ten-story steel frame resisting structure [28]; (a) sections; (b) dead load $35 \mathrm{kN} / \mathrm{m}$;(c) live load $14.6 \mathrm{kN} / \mathrm{m}$; (d) deformed shape of the first mode $T=2.27 \mathrm{~s}$; (e) deformed shape of the second mode $T=0.79 \mathrm{~s}$.

The periods of the first two vibration modes of this structure have the results $T=2.27 \mathrm{~s}$ and $T=0.79 \mathrm{~s}$, respectively. The differences in the periods from the results in [28] are negligible for practical design purposes. The structure results in being flexible, hence it may be considered relevant for investigating the correlation of the $P-\Delta$ effect with seismic design requirements. Six seismic intensity levels are considered in this illustrative test, from a combination of two different peak ground accelerations, $0.2 \mathrm{~g}$ and $0.3 \mathrm{~g}$, and three behavior factors, $q=3,4$, and 5 .

Figure 6 reports the obtained stability factors $\theta$ obtained for the different levels of earthquake loads, by applying a standard response spectrum analysis procedure. The behavior factor significantly affects the intensity of the seismic loads, particularly when the response spectrum method is applied, and the structures exhibit frequencies closer to the plateau of the spectrum. This indicates the importance of the ductility design of the structures coupled with second-order effects. 


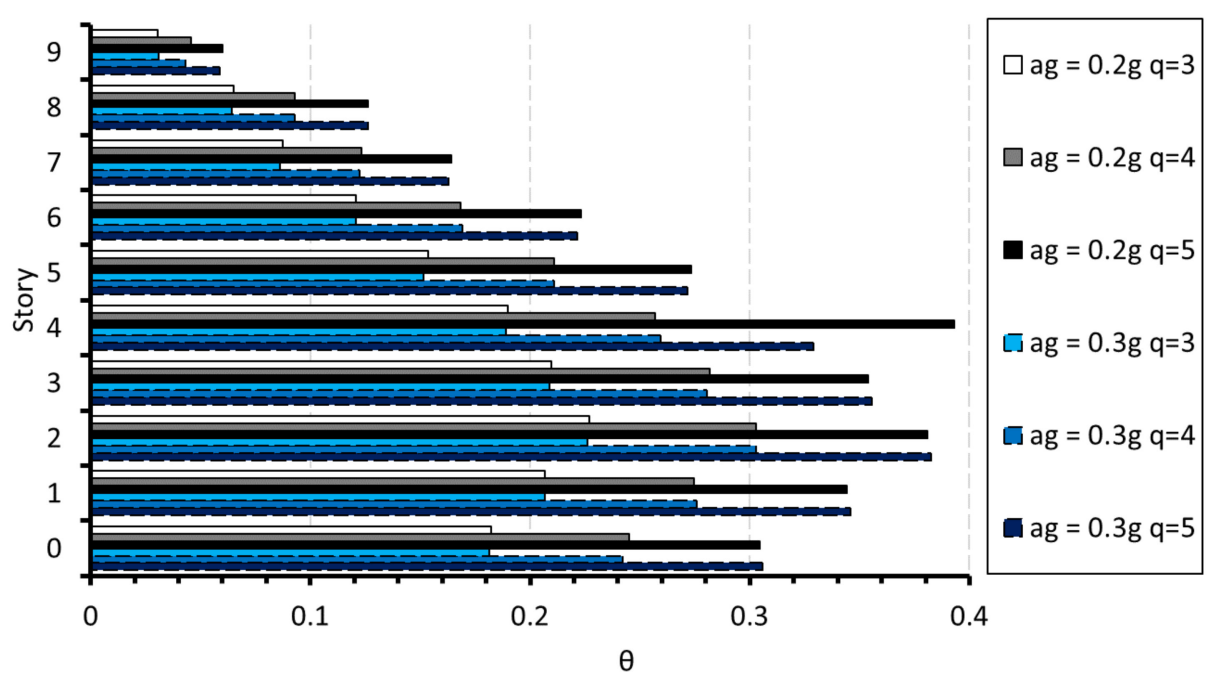

Figure 6. Illustration of the $\mathrm{q}$ factor and the ground acceleration influence in the stability factor, $\theta$ for a 10 -story steel resisting frame.

The design approach including the $P-\Delta$ effect is investigated in five different ways as follows:

1. A simple response spectrum analysis is performed including the geometrical nonlinearities derived from the implementation of a $P-\Delta$ analysis.

2. The deformations derived from simple response spectrum analysis are multiplied with the normal forces and then manually added to the moments obtained from the RS analysis. No moment redistribution is applied here.

3. A simple response spectrum analysis is performed including the nonlinearities derived from $P-\Delta$ analysis assuming that the structure behaves inelastically, according to the approach presented in Section 2.2 for the SDOF systems. The vertical load in the $P-\Delta$ forming stiffness matrix process is multiplied with the $\mathrm{q}$ factor.

4. The results obtained from the response spectrum analysis are amplified by the $1 /(1-\theta)$ factor, assuming the maximum value is obtained for the instability coefficients at each story, as is recommended in [29].

5. The results obtained from the response spectrum analysis are amplified by the $1 /\left(1-\theta_{i}\right)$ factor, estimated to each story. At present, there is no reference to implement this approach, thenceforth the meaning is only to provide a full picture to the expected amplification effect from the $P-\Delta$ analysis, comparable here with the physics approach of the second method.

The results in terms of the maximum moments at the story columns for all the cases are reported in Figure 7. The results obtained by the physical approach of the $P-\Delta$ effect (i.e., the second of the above approaches) highlight a significant increase of the design moment for the columns, up to $75 \%$ for the structure under consideration. The fourth method (i.e., with the stability factor) exhibits a constant increment (if applied automatically as is performed in the present case) of the design moment for guaranteeing the structural stability at the ultimate limit state. This method presents a drawback that it increases the overall acting loads and does not consider any second-order effects in localized elements of the structure (e.g., to the elements close to the base). The way to overcome this drawback is to apply different stability factors at each level but this results in the impractical application of the method for complex structures. The third method seems to follow the amplification trend of the second method, considering the locally induced second-order moments. The automatically implementable method allows for the force's redistribution that is reflected by lower moments compared to the second method, which adds the $P \Delta$ moment at a single column without redistributing it at the adjacent elements. The advantage of the proposed approach is evident even applied for MDOF systems, and not only for SDOF systems, for which the stability factor is primarily conceived. 

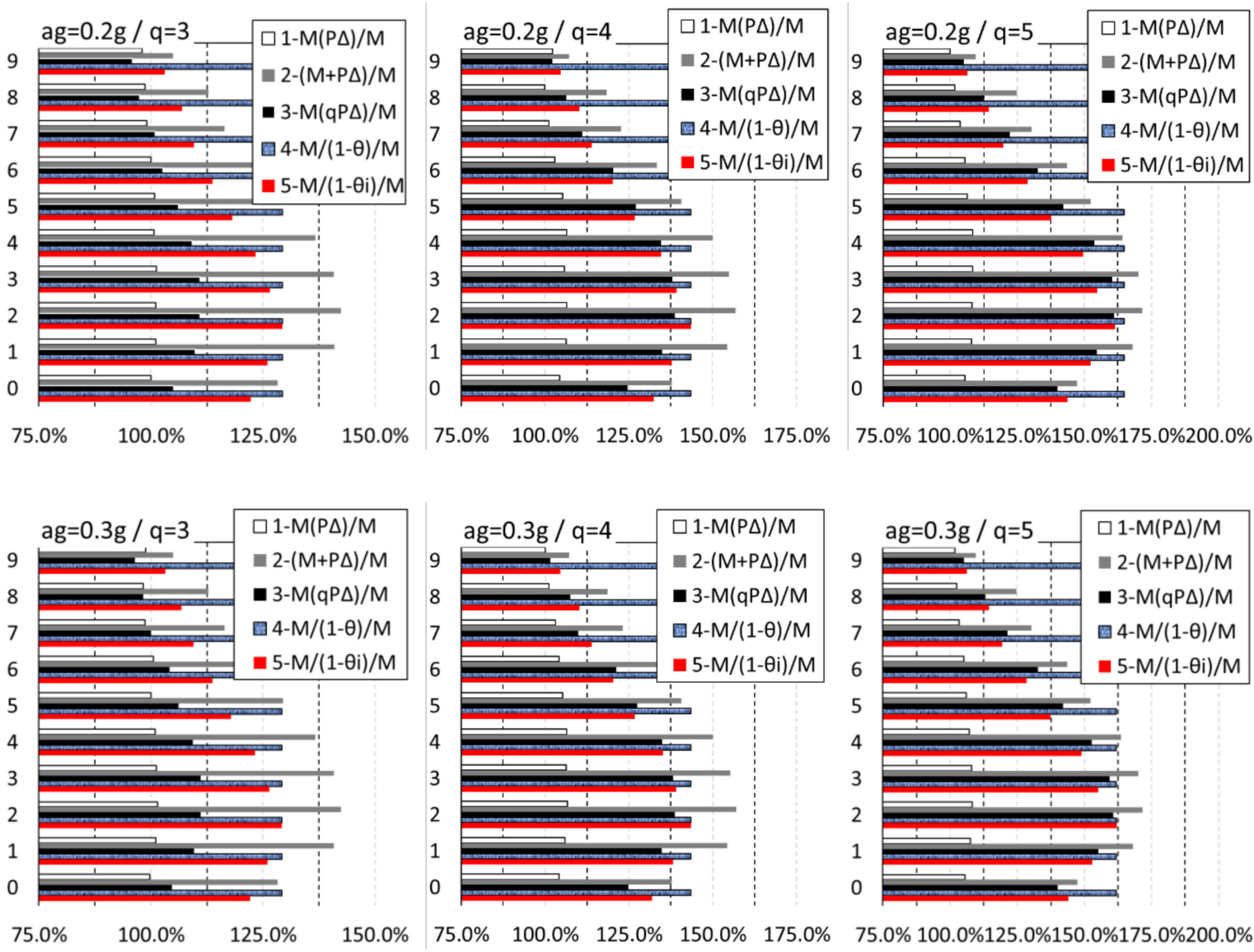

Figure 7. Influence of the $\mathrm{q}$ factor and ground acceleration in the $P-\Delta$ effect of nine-story steel resisting frame structure. Illustration of different approaches for the estimation of the maximum acting moment in the story columns.

\section{The Three-Step Procedure}

In this section, we will summarize the steps to be followed for implementing a $P-\Delta$ analysis for a structure which is subject to large displacement demands due to earthquakes and vulnerable to second-order effects.

As demonstrated in Section 2 of this article, it is quite a challenge to consider adequately the $P-\Delta$ effects in linear analysis during the design phase if the inelastic phase of the structural elements should be taken into account. According to FEMA 450 [29], the stability coefficient $\theta$ shall be permitted to exceed 0.10 if the resistance to lateral forces is determined to increase continuously in a monotonic nonlinear static (pushover) analysis to the target displacement and the $P-\Delta$ effects shall be included in the analysis. In this article, a simple procedure is proposed to perform structural analysis which considers simultaneously $P-\Delta$ effects and the plastic deformations of the structure in an approach suitable for the design phase, applying the following steps:

- $\quad$ Step 1. The inputs for the structural analysis are selected: the peak ground acceleration (PGA) and the behavior factor (q). The selected behavior factor should reflect also the expected ductility of the structure, thenceforth it should neither underestimate nor overestimate such value in order to obtain a realistic design.

- $\quad$ Step 2. Perform a nonlinear analysis considering the geometrical nonlinearity. The vertical forces in this analysis are magnified with the behavior factor in order to consider the amplification of the P- $\Delta$ effects as a result of the inelastic displacements. This analysis will be used as a starting point for the application of successive analysis. 
- Step 3. Perform linear analysis, Response Spectrum analysis, or equivalent seismic analysis using the stiffness matrix of the previous analysis for the determination of the seismic actions. Many software programs, like SAP2000 [30] or other commercial packages [31-33], allow running an analysis using the stiffness matrix of a previous analysis. Hence such a requirement is mandatory for the implementation of the present approach.

The obtained results have automatically included the effect of gravity loads in a pseudo deformed configuration which approximates the effect of the plastic deformations.

\section{Case Studies}

Three case studies from the research of Gupta and Krawinkler [11,34] are used to discuss the P- $\Delta$ effects in light of the stability factor, behavior factor, and the seismic intensity. The case studies summarized here are part of an extensive study on the seismic performance of steel moment-resisting frame structures with fully restrained connections [29]. Briefly, they consist of: (1) a 3-story building designed for Los Angeles conditions (Seismic Zone 3); (2) a 9-story building designed for Los Angeles conditions (Seismic Zone 4); (3) a 20-story building designed for Los Angeles conditions (Seismic Zone 4). The design of the three structures conforms with the Uniform Building Code (UBC-1994) requirements.

All three structures were conceived with perimeter moment-resisting frames that are designed to resist all lateral loads. The interior simple framing is designed to resist only tributary gravity effects. The corresponding gravity loads are the dead loads, $4.6 \mathrm{kN} / \mathrm{m}^{2}(96 \mathrm{psf})$, and the live loads, $2.4 \mathrm{kN} / \mathrm{m}^{2}$ (50 psf). The designed sections of the elements are considered those as reported, and no additional design is conducted by applying different seismic design codes or any update from the current codes. The structures have been tested to different seismic intensity levels, similarly to the tests conducted in Section 2.3. Plan views and elevations of the two buildings are shown in Figure 8 . Detailed information on the building structures can be found in [11,34].

Full complete 3D finite element models for the considered buildings have been created in commercial software SAP2000, which provides the possibility for detailed modeling and the implementation of the structural analyses with interest for this study [30]. It is possible to perform three-dimensional analyses, but for the scope of the research and considering the perfect symmetry of the structures, it was chosen to apply the seismic loads only in one plane.

Initially, modal analyses are conducted in order to verify the congruence of the numerical models with the models developed in [29]. The here-created numerical models have similar periods corresponding to the first fundamental vibration mode with the results of the models developed by Gupta and Krawinkler as reported in [29]. The results are reported in Table 1, and the similarity of the modal frequencies demonstrates the validity of the present models and the subsequent seismic analysis can be performed.

Table 1. Periods of the analyzed building from other studies.

\begin{tabular}{ccc}
\hline \multirow{2}{*}{ Structure } & \multicolumn{2}{c}{ Period [s] } \\
\cline { 2 - 3 } & Mode 1 (Present Study) & Range of Mode 1 From [29] \\
\hline LA 3-Story & $0.9 \mathrm{~s}$ & $0.85-1.03 \mathrm{~s}$ \\
LA 9-Story & $2.03 \mathrm{~s}$ & $1.97-2.34 \mathrm{~s}$ \\
LA 20-Story & $3.65 \mathrm{~s}$ & $3.45-3.98 \mathrm{~s}$ \\
\hline
\end{tabular}



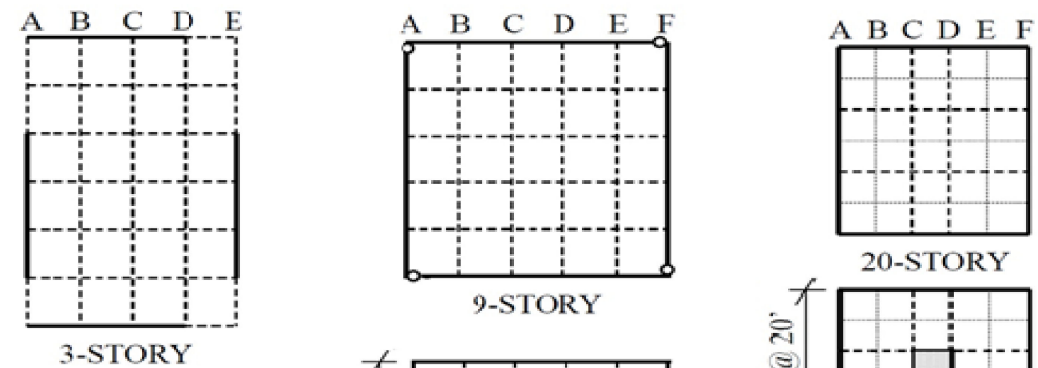

9-STORY
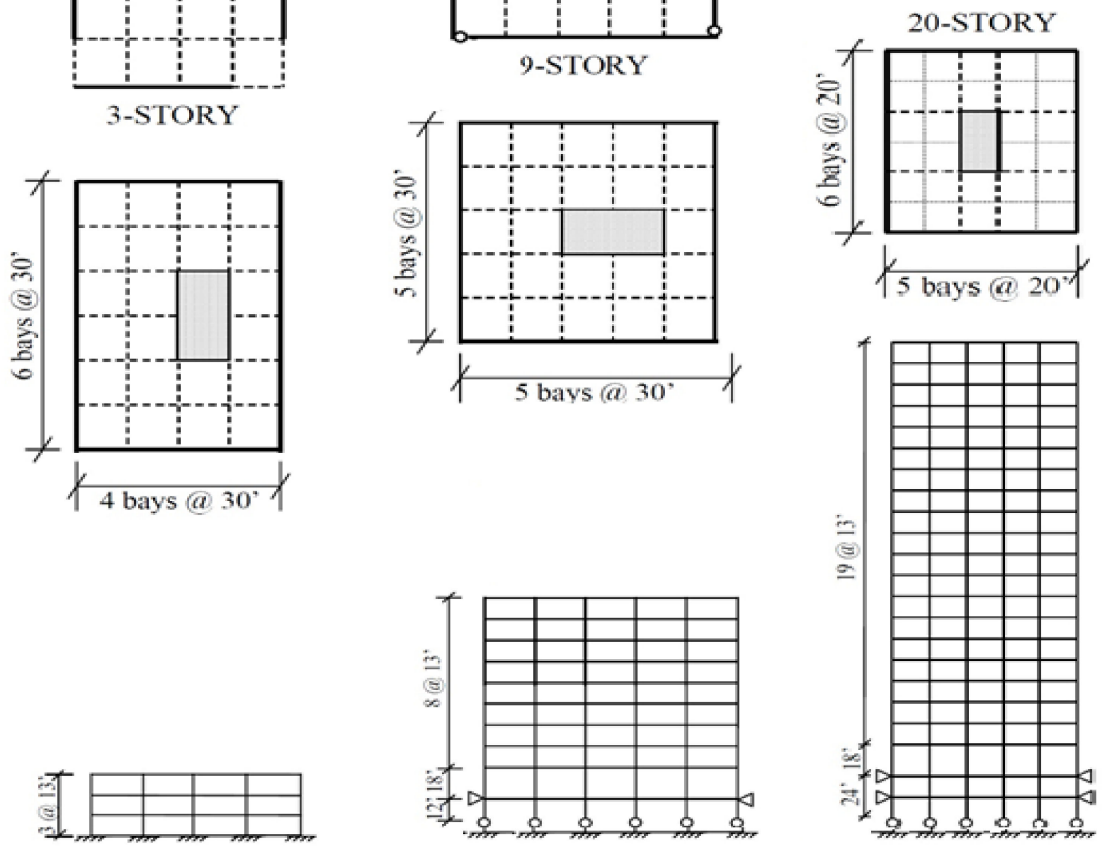

Figure 8. Floor plans and elevations of the considered 3-, 9-, and 20-story buildings [29].

The analyses carried out on the three case studies are similar to those performed in Section 2.3, considering two seismic levels separately for an ag $=0.2$ and ag $=0.3$ and three behavior factors. The results reported in Figures 9-12 show the ratio between the design moment due to the seismic action, with and without $P-\Delta$ effect. The three case studies, representing also different types of structures, exhibit different behaviors (in terms of the necessity to consider the $P-\Delta$ effect).
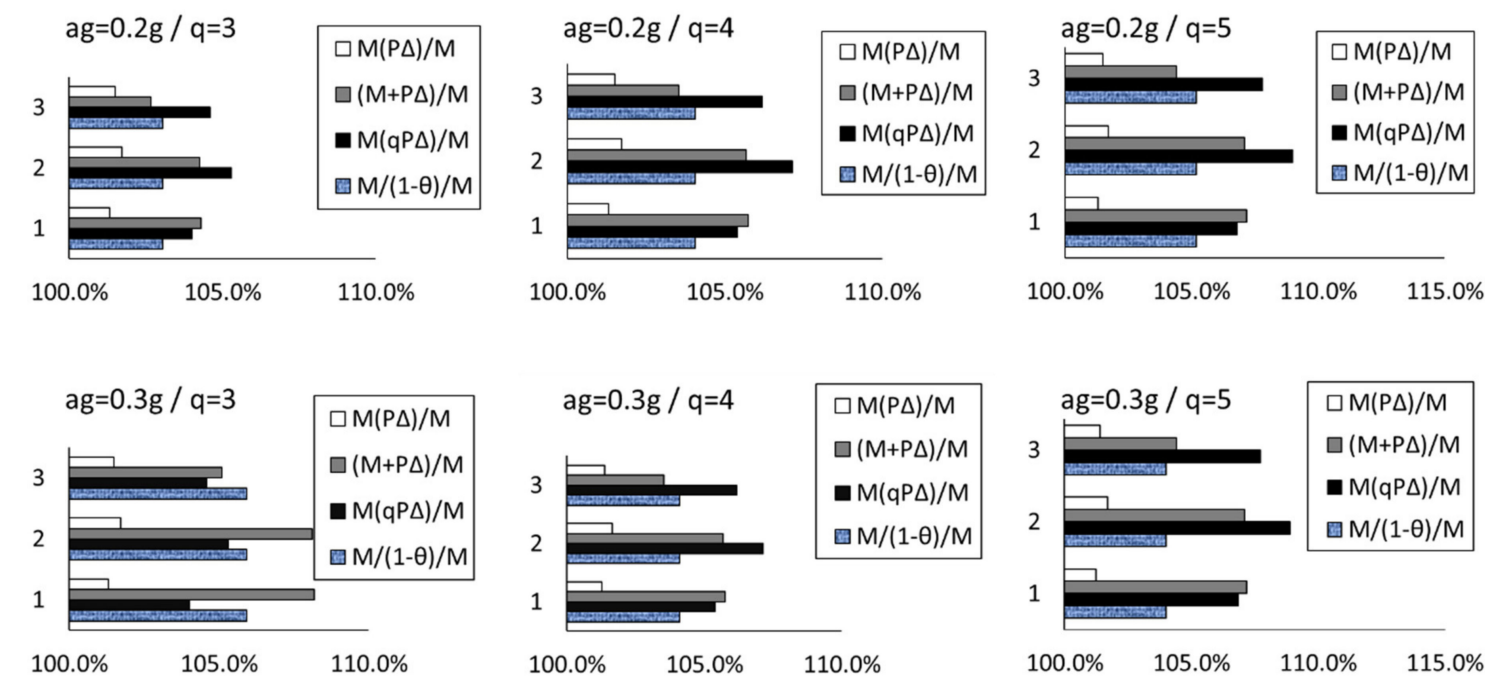

Figure 9. Influence of the $\mathrm{q}$ factor and ground acceleration in the $P-\Delta$ effect of three-story steel resisting frame structure. Illustration of different approaches for the estimation of the maximum acting moment in the story columns. 

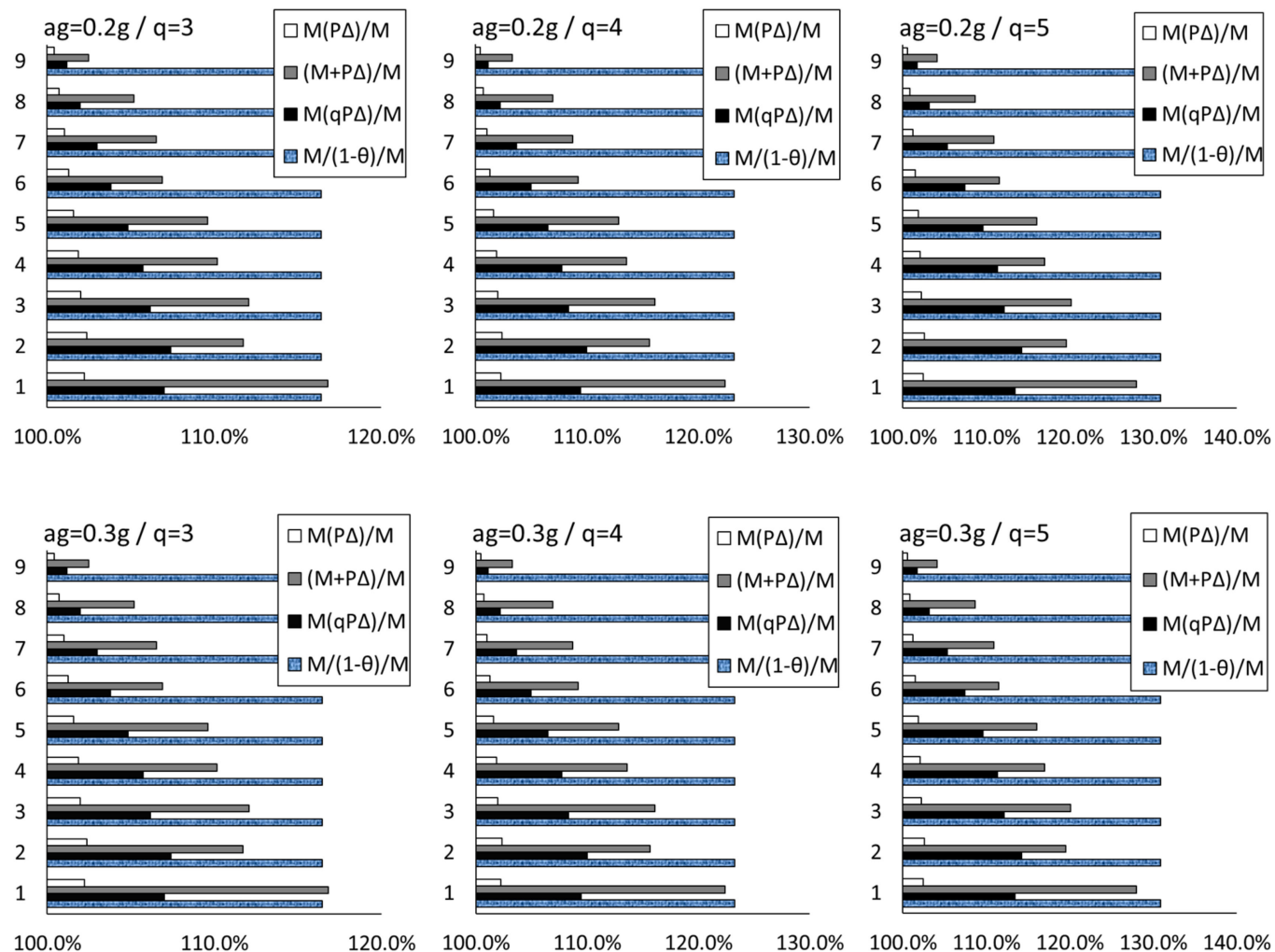

Figure 10. Influence of the $\mathrm{q}$ factor and ground acceleration in the $P-\Delta$ effect of nine-story steel resisting frame structure. Illustration of different approaches for the estimation of the maximum acting moment in the story columns.

In the case of the 3-story building, the $P-\Delta$ effect results in not being significant, while a stability factor lower than 0.1 is computed. The 9-story structure and the 20-story structure exhibit a higher stability factor, around 0.2 and 0.3 , indicating the necessity to consider the $P-\Delta$ effects during the design.

It is evident that each case study would have a different structural response to the $P-\Delta$ effects, depending on the seismic level and behavior factor.

Cases such as the 9-story building highlight the possibility that the stability factor would overestimate the second-order moments, while the 20-story building shows the opposite. Up to a difference of $200 \%$ was registered for the 20-story structure, highlighting a high sensitivity toward the $P-\Delta$ such structure exhibits. From a design perspective, it is necessary to understand the behavior of the structure, and it is obvious that the present case studies would behave not as desired or unpredictably compared to the expected one.

The results for all the investigated case studies highlight the necessity to study the $P-\Delta$ effect in a more accurate fashion. For the low-height buildings, the stiffness of the structure impels relatively high seismic forces and the change in the stiffness matrix causes a slight decrement of the lateral acting loads. However, such structural behavior is not due to the incorporation of the plastic deformations in the added second-order moment. For the tallest structure, it is expected that the lateral loads are slightly influenced by the period shift, however, the magnitude of the vertical loads and the lateral flexibility of the structure play a crucial role. A double of the acting moment for the ultimate configuration shows a high potential that similar structures would form soft stories even when the structural elements respect the design requirements. Such cases may be classified as highly vulnerable to a loss of stability. In fact, the proposed approach, on performing nonlinear static analysis with the vertical loads, is an approximation for buckling analysis, where the lateral inelastic deformations from seismic loads could amplify the effect of the vertical loads and cause a matrix singularity [24]. 

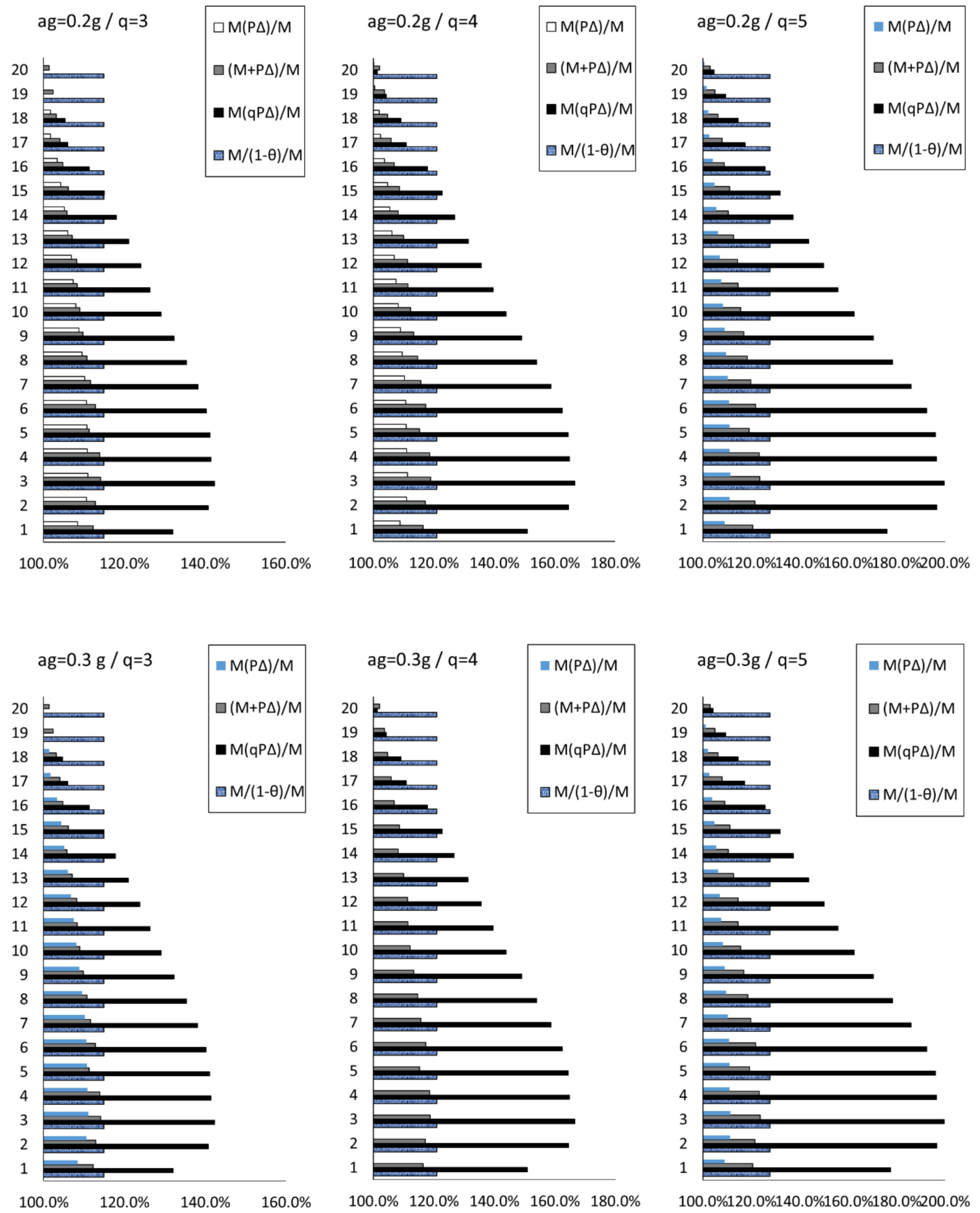

Figure 11. Influence of the $\mathrm{q}$ factor and ground acceleration in the $P-\Delta$ effect of 20-story steel resisting frame structure. Illustration of different approaches for the estimation of the maximum acting moment in the story columns.

The method here proposed and the obtained results demonstrate the high vulnerability of flexible structures to sidesway collapse. From a safety perspective, it is helpful to understand the behavioral characteristics of the designed structure from a pushover analysis to evaluate the influence of $P-\triangle$ effects on the dynamic response and the inelastic capabilities of the structure [35].

From the case study, a significant difference between the proposed method and the existing one is found for the 9-story and 20-story building. The following graphs synthesize for the above structures the difference in the resisting moment between the proposed method and the stability factor method. Each graph in the image represents a seismic scenario as previously described. Depending on the 
structure's height and the seismic scenario, we take a large range of the results to differ approximately $80 \%$ to $160 \%$. These results show the difference of the proposed approach and highlight the sensitivity of the structures toward second-order effects and plastic capabilities.
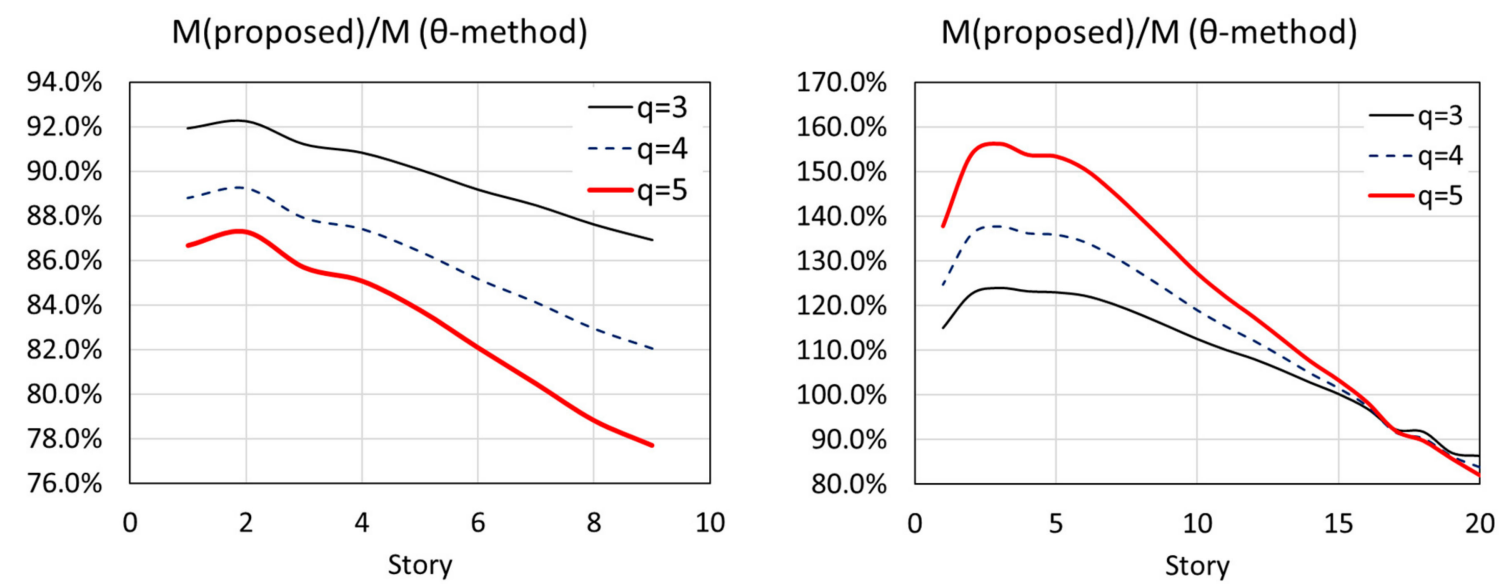

Figure 12. The difference between the proposed method and the stability factor method in estimating the design resisting moment.

\section{Conclusions}

This paper proposes a practical approach for addressing the design of ductile structures vulnerable to the second-order effects. The architectural demands very often drive the engineering design to relatively flexible structures, while on the other side, the seismic demands impede for a more ductile behavior.

The proposed procedure is aimed to overcome some drawbacks of the current practice regarding the $P-\Delta$ effects, related mostly to the stability factor approach. In this paper, we showed by comparing with other approaches that a simple procedure, implementable in three easy steps, may be more practical in terms of time efficiency (compared to nonlinear analysis) and result accuracy. The stability factor coefficient has resulted in a very efficient and straightforward approach for SDOF systems, whereas some issues arise in the case of MDOF systems. One of the significant aspects as also highlighted here is related to the multiple values that this coefficient takes for different levels. The application of a different correction coefficient for each story restricts the applicability of some analyses, like response spectrum analysis. Moreover, the selection of the maximum value from the different stability factors may result in an overestimation of the seismic effects, while the proposed approach evaluates the seismic demands by manipulating the stiffness matrix of the structure, such as by properly estimating the internal forces at the limit state of a structural element subjected to horizontal and vertical loads, for a deformed configuration compatible with the evolution of plastic phases.

The numerical analysis carried out on the selected case studies highlighted that the lower levels were more vulnerable to such combined effects. Based on the selected design parameters, the additional design moments due to $P-\Delta$ effects varied from approximately 25 to $100 \%$, which is very significative of the strength capacity of the elements. These results propose the need to design these structures with higher resisting capabilities, which will result in a better redistribution of the plastic hinges through the structure during strong earthquake sequences.

This research was focused on the response spectrum method for estimating the seismic loads, thenceforth the traditional pushover analysis presents challenges counting for the higher modes. It is foreseen to extend this research on simplified representations of lateral seismic loads which can later be compared with an equivalent pushover analysis mimicking the same load pattern in a very straightforward fashion. 
Author Contributions: Conceptualization (R.S., G.A., H.B.); Methodology (R.S., G.A., H.B.), Numerical Simulations (G.A.), Draft Preparation (R.S., G.A.), Editing (H.B., R.S., G.A.), Supervision (H.B.)

Funding: This research received no external funding.

Conflicts of Interest: The authors declare no conflict of interest.

\section{References}

1. Fema-356 Prestandard and Commentary for the Seismic Rehabilitation of Buildings; Federal Emergency Management Agency: Washington, DC, USA, 2000.

2. Fardis, M.N. Seismic Design, Assessment and Retrofitting of Concrete Buildings; Geotechnical, Geological, and Earthquake Engineering; Springer: Dordrecht, The Netherlands, 2009; Volume 8, ISBN 978-1-4020-9841-3.

3. DPCM. Linee Guida per la Valutazione e la Riduzione del Rischio Sismico del Patrimonio Culturale con Riferimento alle Norme tecniche per le Costruzioni di cui al Decreto del M.I.T del (2008); Decreto del Presidente del Consiglio dei Ministry: Rome, Italy, 2011.

4. Grünthal, G. European Macroseismic Scale 1998; European Center of Geodynamics and Seismilogy: Walferdange, Luxembourg, 1998; Volume 15, ISBN 2879770084.

5. Gioncu, V.; Mazzolani, F. Ductility of Seismic-Resistant Steel Structures, 1st ed.; CRC Press: Boca Raton, FL, USA, 2002; p. 720.

6. Chopra, A.K. Dynamics of structures: Theory and Applications to Earthquake Engineering, 4th ed.; Prentice Hall: Upper Saddle River, NJ, USA, 2011; ISBN 013156174X.

7. Dowrick, D.J. Earthquake Resistant Design and Risk Reduction; John Wiley \& Sons, Inc.: Hoboken, NJ, USA, 2009; ISBN 9780470747025.

8. Williamson, E.B. Evaluation of Damage and $\mathrm{P}-\Delta$ Effects for Systems Under Earthquake Excitation. J. Struct. Eng. 2003, 129, 1036-1046. [CrossRef]

9. Montgomery, C.J. Influence of P-Delta effects on seismic design. Can. J. Civ. Eng. 2010, 8, 31-43. [CrossRef]

10. Fema P-58-1 Seismic Performance Assessment of Buildings-Methodology; Federal Emergency Management Agency: Washington, DC, USA, 2012; Volume 1.

11. Gupta, A.; Krawinkler, H. Dynamic P-Delta Effects for Flexible Inelastic Steel Structures. J. Struct. Eng. 2002, 126, 145-154. [CrossRef]

12. Pettinga, D.; Priestley, N. Accounting for P-Delta effects in structures when using direct displacement-based design. In Proceedings of the 14th World Conference Earthquake Engineering, Beijing, China, 12-17 October 2008; pp. 1-8.

13. Lignos, D.G.; Putman, C.; Krawinkler, H. Application of simplified analysis procedures for performance-based earthquake evaluation of steel special moment frames. Earthq. Spectra 2015, 31, 1949-1968. [CrossRef]

14. EC-8-P-1. Eurocode 8: Design of Structures for Earthquake Resistance-Part 1: General Rules, Seismic Actions and Rules for Buildings; European Commission: Brussels, Belgium, 2014.

15. Kirsch, U. Reanalysis of Structures: A Unified Approach for Linear, Nonlinear, Static and Dynamic Systems; Springer: Dordrecht, The Netherlands, 2010; Volume 151, ISBN 9781402081972.

16. Shehu, R. The P- $\Delta$-Ductility Effect: Overview the Effect of the Second Order in the Ductil Structures. Eur. Sci. J. 2014, 3, 7881.

17. MacRae, G.a. P- $\Delta$ Effects on Single-Degree-of-Freedom Structures in Earthquakes. Earthq. Spectra 1994, 10, 539. [CrossRef]

18. Sucuoğlu, H.; Akkar, S.; Halûk, S.; Sinan, A. Basic Earthquake Engineering; Springer: Dordrecht, The Netherlands, 2014; ISBN 9783319010250.

19. Ministero delle Infrastrutture e dei Trasporti Aggiornamento delle "Norme Tecniche per le Costruzioni"-NTC. Gazzetta Ufficiale 2018, 1-198.

20. Priestley, M.J.N. Performance Based Seismic Design; Bulletin of the New Zealand Society for Earthquake Engineering: Wellington, New Zealand, 2000; pp. 325-346.

21. Vamvatsikos, D.; Kazantzi, A.K.; Aschheim, M.A. Performance-Based Seismic Design: Avant-Garde and Code-Compatible Approaches. ASCE J. 2016, 2, 1-9. [CrossRef]

22. Aschheim, M.; Montes, E.H. The representation of P- $\Delta$ effects using Yield Point Spectra. Eng. Struct. 2003, 25, 1387-1396. [CrossRef] 
23. Black, E.F. Use of stability coefficients for evaluating the P- $\delta$ effect in regular steel moment resisting frames. Eng. Struct. 2011, 33, 1205-1216. [CrossRef]

24. Wilson, E.L. Three-Dimensional Static and Dynamic Analysis of Structures: A Physical Approach with Emphasis on Earthquake Engineering, 3rd ed.; Computers \& Structures, Inc.: Berkeley, CA, USA, 2002; ISBN 0923907009.

25. Paulay, T.; Priestley, M.J.N. Seismic Design of Reinforced Concrete and Masonry Buildings; Wiley \& Sons: Hoboken, NJ, USA, 1992; ISBN 9780470172841.

26. Fajfar, P. A Nonlinear Analysis Method for Performance-Based Seismic Design. Earthq. Spectra 2000, 16, 573-592. [CrossRef]

27. Clough, R.W.; Penzien, J. Dynamic of Structures, 3rd ed.; McGraw-Hill: New York, NY, USA, 1993.

28. Anderson, J.C.; Bertero, V.V. Uncertainties in Establishing Design Earthquakes. J. Struct. Eng. 2008, 113, 1709-1724. [CrossRef]

29. FEMA 450 Nehrp Recommended Provisions for Seismic Regulations for New Buildings and Other Structures; Part 1; Federal Emergency Management Agency: Washington, DC, USA, 2003; p. 338.

30. CSI. CSI Analysis Reference Manual; CSI: Walnut Creek, CA, USA, 2015.

31. Simulia, D.S. Abaqus 6.14 Documentation; Vélizy-Villacoublay: Paris, France, 2014.

32. Diana, F.E.A. Diana User's Manual; Release 10.2; Diana Inc.: Delft, The Netherlands, 2017.

33. ANSYS Inc. Element Reference for ANSYS Mechanical APDL; ANSYS Inc.: Canonsburg, PA, USA, 2012.

34. Gupta, A.; Krawinkler, H. Seismic Demands for Performance Evaluation of Steel Moment Resisting Frame Structures; Stanford University: Stanford, CA, USA, 1999.

35. Bernal, D. Instability of buildings during seismic response. Eng. Struct. 1998, 20, 496-502. [CrossRef]

(C) 2019 by the authors. Licensee MDPI, Basel, Switzerland. This article is an open access article distributed under the terms and conditions of the Creative Commons Attribution (CC BY) license (http://creativecommons.org/licenses/by/4.0/). 